\title{
Pathophysiological and Clinical Aspects of Venous and Arterial Thrombosis
}

'In the end, all progress in thrombosis prevention and treatment will stem from better understanding of the fundamental mechanisms involved. It is some light in some laboratory that some day will make the difference. But the road to that end may be deceivingly curved and the day discouragingly far'. In these words we started our preface to the previous collection of lectures from the 15th International Congress on Thrombosis organized in September 1998 in Antalya, by Prof. Orhan Ulutin, for the Mediterranean League against Thrombosis and the Thrombosis Society of Turkey.

Neither the patients nor our clinical colleagues can wait for that day. It is one of the challenges and charms of clinical medicine that it has to act with the available knowledge, even when incomplete. With the advent of evidence-based medicine, the last decennia have shown us that the approach from the practical side of medicine to the difficult problem of arterial and venous thrombosis is at least as valuable as the approach from the side of the basic sciences. There is even more to it: medicine-based evidence is an important contribution to the development of the basic understanding of pathogenetic mechanisms. Therefore, this volume with pathophysiological and clinical aspects of thrombosis is the natural complement to the volume with basic aspects on thrombosis that appeared earlier.

Again we should like to express our gratitude to Prof. Ulutin and the Thrombosis Society of Turkey for allowing us to publish these state-of-the-art lectures here, again also on behalf of our readers that they can now find this information in the peer-reviewed literature.

H.C. Hemker, Maastricht

S. Lévy-Toledano, Paris

\section{KARGER}

(C) 1999 S. Karger AG, Basel

Fax +41 613061234

E-Mail karger@karger.ch

www. karger.com

Accessible online at:

www.karger.com/journals/hae 